\title{
Local compression fatigue property of roll core sandwich panel
}

\author{
Yukiyoshi KOBAYASHI*, Yoshinao KISHIMOTO*, Toshihisa OHTSUKA* and Akira KARATSU** \\ *Department of Mechanical Engineering, Tokyo City University \\ 1-28-1 Tamadutsumi, Setagaya-ku, Tokyo 158-8557, Japan \\ E-mail: ykoba@tcu.ac.jp \\ ${ }^{* *}$ Graduate Student, Tokyo City University \\ 1-28-1 Tamadutsumi, Setagaya-ku, Tokyo 158-8557, Japan
}

Received 24 July 2014

\begin{abstract}
When the honeycomb core sandwich panel (hereafter, HSP for brevity) is used as a floor panel, a dent is formed on the surface of it. If the depth of dent was deeper, it is changed into a new one. In order to change it efficiently, it is necessary to study a period for use as the floor panel applied the repetition of local compression load for the longitudinal direction of honeycomb core (hereafter, fatigue life for brevity). The local compression fatigue tests of peripherally clamped HSPs were carried out. In this study, it is attempted to clarify the local compression fatigue property of roll core sandwich panel which was superior to the honeycomb core sandwich panel in the manufacturing cost and the mechanical property. From the obtained results, the follows were summarized; 1) There were three fracture patterns such as a tensile and a shearing types that fractured on the border of the indenter contact region and the noncontact region of specimen and a shearing around dent type that fractured on the periphery of a dent formed during the indentation. 2) The stress state at a crack initiation site governed a fatigue life. 3) Not a core shape but a cell size influenced the fatigue life.
\end{abstract}

Key words : Fatigue, Laminated construction, Structural mechanics, Design, Sandwich panel

\section{Introduction}

The honeycomb core sandwich panel (hereafter, HSP for brevity) is a type of structural panel where a honeycomb core is bonded in between two flat sheets (hereafter, face sheets for brevity). It is excellent in specific tensile strength and specific rigidity while maintaining light weight (Noguchi, 1985, the book of Satho,1995, Miyauchi, 1999, Gibson et al., 1993). From the viewpoint of weight saving, HSP is now used for floor panels of aircrafts and wall panels of vehicles (Takeichi, 2002a, 2002b, 2002c). Although the HSP can resist loads applied uniformly over the entire panel, a locally applied load can easily produce a dent near the point of action on the face sheet because of its structure (Goldsmith et al.,1992, Moriarty, 1993). Particularly, when the local compression load as people step on is applied on the panel made by HSP, it resulted in the formation of irregularities. The floor panel needs to be replaced as the irregularity becomes conspicuous. Therefore, it is desirable to determine the maximum use period for HSPs repeated local compression loads to employ an appropriate maintenance and a safer design.

To simulate the situation of the HSPs used as the floor panel, a fatigue test has been performed to study how the dent grows on the HSP and how fracturing takes place. Based on obtained results, floor panel design guidelines have been proposed. In this fatigue test, the peripheral section of the HSP was fixed and local compression loads were repeatedly applied to the center (Tsujita et al., 2009, Kobayashi et al., 2011, 2012). The method of clamping the test specimen and the shape of the indenter was determined by referencing a drop weight test that simulated collisions with a flying object, because the formation of the dent was evaluated by using this test method (Watanabe et al., 2003).

The results obtained from previous studies are as follows (Kobayashi et al., 2011, 2012). Three fracture patterns were confirmed. In face sheets contacting the indenter, there were two types of fatigue fractures at the boundary between the contact and noncontact sections with the indenter. These are distinguished by the stress state: tensile stress 
or shearing stress (hereafter, tensile type fracture or shearing type fracture for brevity). The third type of fatigue fracture was caused by the superimposition of shearing stress at a position where the face sheet bends in two steps at the periphery of a dent formed during the indentation (hereafter, shearing around the dent type fracture for brevity). The stress at the fracture initiation site was highest in tensile type fractures, followed by that in shearing around the dent type fractures, and least in shearing type fractures. Because the fracture pattern changes from the tensile to the shearing type, it was found that the shearing fractures took place even when the stress was reduced to below half the stress at which a tensile fracture took place. This behavior must be considered to achieve a safer design.

The roll core sandwich panel (hereafter, RSP for brevity) is more economical than HSP because it is easier to produce. If the core densities of both panels were same, the RSP has superior mechanical properties to the HSP. This is because the RSP has a broader area where the panel is strengthened by deformation constraints enacted by overlapping cores (Kobayashi et al., 2010). In order to consider the possibilities of the use of RSP, local compression fatigue tests were carried out by using the RSP. In addition, the obtained results in this study were compared with those of HSP obtained in the previous studies.

\section{Experimental Procedures}

\subsection{Specimen}

Constituent materials are shown in Table 1. The RSP and the HSP for material comparison were used for test specimens. The overall view of the specimen and cell shapes are shown in Figures 1 and 2, respectively. Both panels are composed of face sheets and a core. The material of the face sheet is A1100, with a dimension of $200 \mathrm{~mm} \times 200$ $\mathrm{mm}$, and 3 kinds of thicknesses: $h_{f}=0.3,0.6$, and $0.8 \mathrm{~mm}$. The cores used in this study are the roll core and the honeycomb core. The material for both cores is A1100, with a core height of $20 \mathrm{~mm}$ and a cell wall thickness of $t_{c}=$ $0.08 \mathrm{~mm}$. The shape and dimensions of the roll core are shown in Figure 2(a). The area surrounded by the double dot dash lines in the figure is the unit cell in the roll core, and there are 6 points at which the cell walls overlap. In a unit cell, The upper and lower sides and the right and left sides are considered as one point because of the cell's continuity. Therefore, the number of points where the cell wall overlaps is equivalent to 4 . The shape and dimensions of the honeycomb core used as the

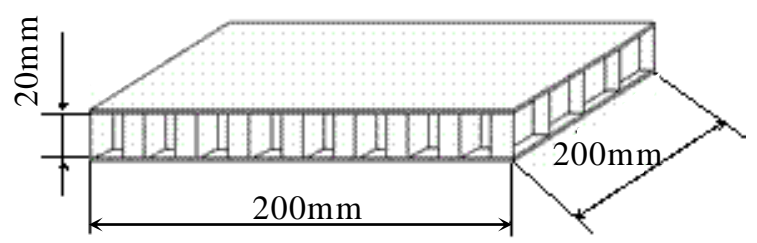

Fig. 1 Specimen.

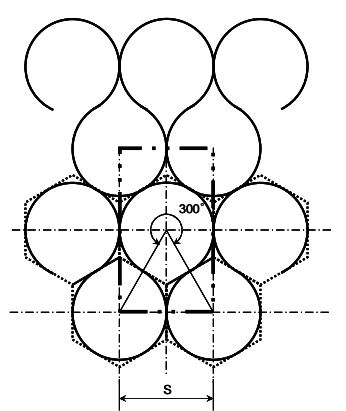

(a) Roll core

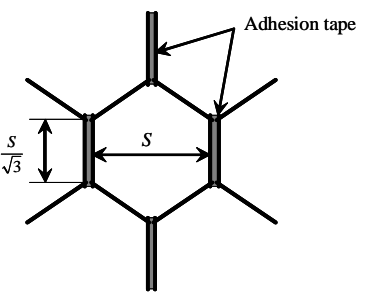

(b) Honeycomb core

Fig.2 Shape of cores.

Table 1 Specimen constituent materials and size.

\begin{tabular}{|c|c|c|c|}
\hline \multirow{3}{*}{ Face Sheet } & \multicolumn{2}{|c|}{ Material } & A1100 \\
\hline & \multicolumn{2}{|c|}{ Thickness $h_{f}[\mathrm{~mm}]$} & $\begin{array}{c}0.3,0.6 \\
0.8\end{array}$ \\
\hline & \multicolumn{2}{|c|}{ Young's modulus [GPa] } & 70 \\
\hline \multirow{3}{*}{ Core } & \multicolumn{2}{|c|}{ Material } & A1100 \\
\hline & \multicolumn{2}{|c|}{ Thickness $t_{c}[\mathrm{~mm}]$} & 0.08 \\
\hline & $\begin{array}{c}\text { Cell size } S \\
{[\mathrm{~mm}]}\end{array}$ & $\begin{array}{c}\text { Roll core } \\
\text { Honeycomb core }\end{array}$ & $\begin{array}{l}10 \\
8.7 \\
\end{array}$ \\
\hline Adhesive sheet & \multicolumn{3}{|c|}{ NB102 made by Newport corporation } \\
\hline
\end{tabular}


comparison material is shown in Figure 2(b). There are 50\% each of double and single walls in a unit cell, because the honeycomb core is manufactured by the Owari style. The cell size is set to $10 \mathrm{~mm}$ for RSP and $8.7 \mathrm{~mm}$ for HSP, such that the densities in both core types are approximately equal. The compressive strength in the thickness direction of the roll core is $1.6 \mathrm{MPa}$, whereas the compressive strength in the thickness direction of the honeycomb core is $1.1 \mathrm{MPa}$. As described in a previous study (Kobayashi et al., 2010), the compressive strength in the thickness direction of roll core is 1.4 times higher than that of honeycomb core because the cell walls in the roll core overlap in more areas in the honeycomb core. In addition, the cell size in the roll core is 1.15 times bigger than that in the honeycomb core.

The test specimen was hot-formed in an electric furnace for $150 \mathrm{~min}$ at $150{ }^{\circ} \mathrm{C}$, after the core material were sandwiched from both sides with face sheets interposed an adhesive sheet between the core and the face sheet.

\subsection{Experimental Procedures}

Because the formation of the dent has been evaluated by a drop weight test simulating the collision of a flying object (Goldsmith et al., 1992, Moriarty, 1993, Watanabe et al., 2003), a series of local compression fatigue tests were carried out by repeatedly pressing a hemispheric indenter with a radius of $\mathrm{RI}=30 \mathrm{~mm}$ [Figure $3(\mathrm{a})$ ] on the center of a peripherally clamped test specimen at a frequency of $1 \mathrm{~Hz}$. The tested part is $140 \mathrm{~mm} \times 140 \mathrm{~mm}$. The diagram of the clamping method of the specimen is shown in Figure 3 (b). A space $(30 \mathrm{~mm})$ was left beneath the specimen for deflection of shelf. During the local compression fatigue test, the load was measured with a load cell. The displacement of the indenter was measured with a displacement gauge under the assumption that it was equivalent to the center displacement of the face sheet where the indenter contacts. The center displacement of the face sheet for the minimum compression load within one cycle was used as the residual displacement. The fatigue test was continued until a significant increase was confirmed in the residual displacement. In other cases, the test was discontinued when the number of repetitions exceeded $2.5 \times 10^{5}$ times, where no cracking was observed on the face sheet near the indenter contact point and no remarkable increase in the residual displacement was confirmed during the test.

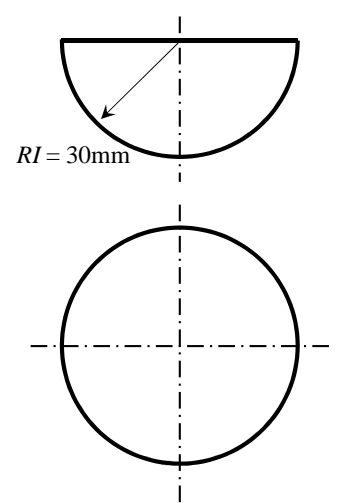

(a) Shape of Indenter

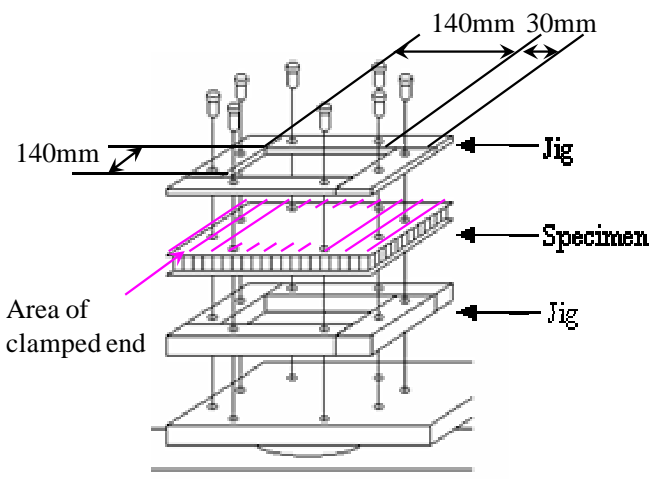

(b) Peripherally clamped specimen

Fig.3 Method to peripherally clamped specimen. All peripheral of specimen was clamped by 4 jigs of $30 \mathrm{~mm}$ in width and 8 bolts. The tested parts of specimen was $140 \mathrm{~mm} \times 140 \mathrm{~mm}$.

\section{Experimental results and discussion}

\subsection{Relationship between residual displacement and the number of cycles}

By changing the thickness of the face sheet and the maximum load value, 3 local compression fatigue tests were performed for each test condition. From the obtained test results, the deformation behavior of the specimen was examined. Figure 4 shows examples of the relationship between the residual displacement and the number of cycles.

Figure 4 shows that the residual displacement of both panels increased linearly on a gentle incline after the start of the test for all conditions. Subsequently, the residual displacement increased sharply from the region after the red (RSP) or white (HSP) plot in the figure. It was visually observed that a crack occurred on the face sheet near the indenter contact point at the start of this event (the red or white plot), which propagated afterwards. For both panels, the region where the displacement increased linearly on a gentle incline accounted for the majority of cycles. Therefore, it was 
decided that the duration up to the accelerating region is the estimated usable period (hereafter, fatigue life $N_{t}$ for brevity).

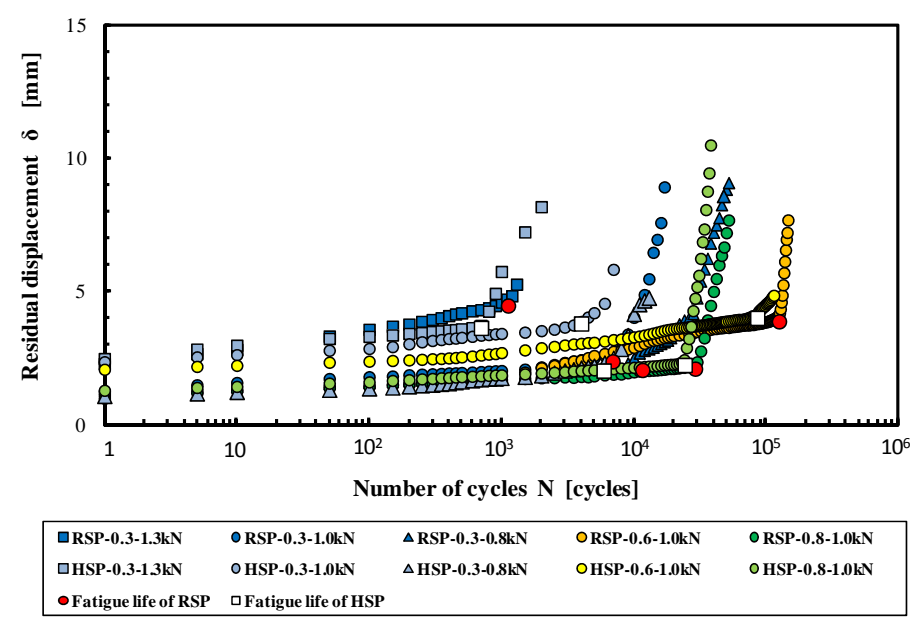

Fig.4 Relationships between residual displacement and the number of cycles.

The legend shows the types of specimens used, the face sheet thickness, and load condition. Red circles and white squares indicate the values of the time at which a crack was visually observed on the face sheet near the indenter contact point during the test. The duration up to this event is defined as the estimated usable period (fatigue life).

\subsection{Fracture patterns}

Figure 5 shows photographs of the specimen after the test. As reported in a past study, the fracture patterns were

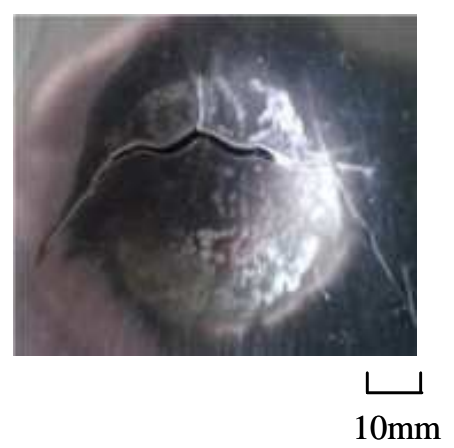

(a) Tensile type

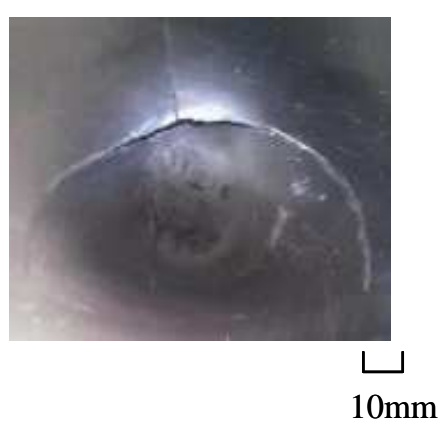

(b) Shearing around dent type (RSP, $h_{f}=0.6 \mathrm{~mm}, P_{\max }=1.0 \mathrm{kN}$ )

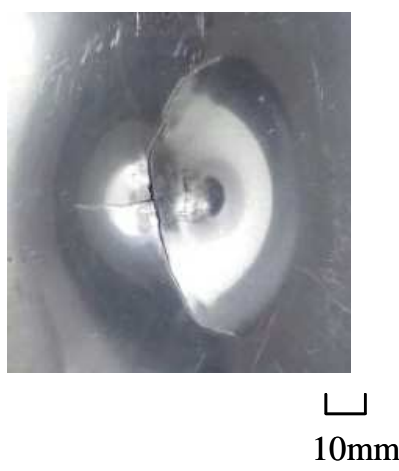

(c) Shearing type (HSP, $h_{f}=0.8 \mathrm{~mm}, P_{\max }=1 \mathrm{kN}$ )

( RSP, $h_{f}=0.3 \mathrm{~mm}, P_{\max }=1.0 \mathrm{kN}$ )

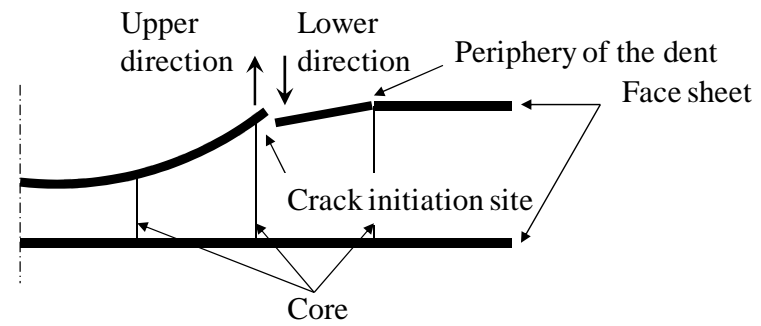

(d) Schematic model of a difference in the vertical direction of the crack surface for shearing around dent type
Crack initiation site

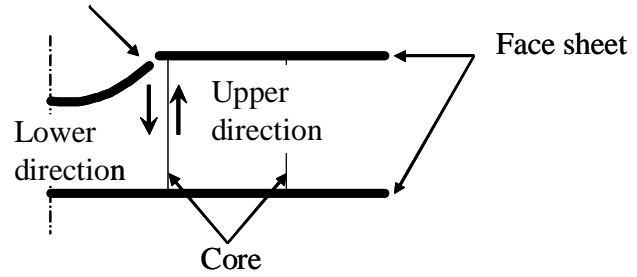

(e) Schematic model of a difference in the vertical direction of the crack surface for shearing type

Fig.5 Fracture Patterns. 
classified into three types (Kobayashi et al., 2011, 2012). The picture in Figure 5 (c) was excerpted from the abovementioned study (Kobayashi et al., 2012), because no shearing fractures was observed from RSP within this test condition. In the specimen whose fracture surface is shown in Figure 5 (a), the superimposed tensile stress caused the formation of a crack in the middle of the dent, especially on the border of the indenter contact region and the noncontact region of the specimen. Hereafter, this type of fracture pattern is called as the tensile type. In the specimens shown in Figure 5 (b) and (c), a difference in the vertical direction of the crack surface, which is an evidence of the mode II type crack was observed. Figure 5 (d) and (e) shows schematic models of the difference in the vertical direction of the crack surface for Figure 5 (b) and (c) respectively. In the image shown in Figure 5 (b) and the schematic model shown in Figure 5 (d), the crack surface near the center was located in the upper direction and the distant crack surface from the center was located in the lower direction as shown in Figure 5 (d). The crack surface located in the upper direction propagated along the core. Furthermore, the face sheet contacting the indenter bent in two steps at two points, one at the crack initiation site and one on the periphery of the dent. The distance between these

Table 2 Matrix of Fracture Patterns of RSP

\begin{tabular}{|c|c|c|c|c|c|c|c|}
\hline Specimen & $\begin{array}{c}\text { Face sheet } \\
\text { thickness } \\
h_{f} \\
\mathrm{~mm}\end{array}$ & $\begin{array}{l}\text { Maximum } \\
\text { load } \\
P_{\max } \\
\mathrm{kN}\end{array}$ & $\begin{array}{l}P_{\max } / h_{f} \\
\mathrm{kN} / \mathrm{mm}\end{array}$ & $\begin{array}{c}\text { Fracture } \\
\text { pattern }\end{array}$ & $\begin{array}{l}\text { Distance to } \\
\text { crack initiation } \\
\text { site } \\
r \text { or } a \\
\mathrm{~mm}\end{array}$ & $\begin{array}{c}\text { Fatigue life } \\
\qquad N_{t}\end{array}$ & $\begin{array}{c}\text { Maximum stress at } \\
\text { crack initiation site } \\
\sigma_{\max } \text { or } \tau_{\max } \\
\mathrm{MPa}\end{array}$ \\
\hline \multirow{5}{*}{ RSP } & \multirow{3}{*}{0.3} & 1.3 & 4.3 & Tensile & $\begin{array}{l}6.8 \\
6.3 \\
6.1 \\
\end{array}$ & $\begin{array}{l}1.1 \times 10^{3} \\
1.0 \times 10 \\
1.6 \times 10^{2}\end{array}$ & $\begin{array}{l}101 \\
109 \\
113\end{array}$ \\
\hline & & 1.0 & 3.3 & $\begin{array}{l}\text { Shearing } \\
\text { around } \\
\text { dent }\end{array}$ & $\begin{array}{c}9.2 \\
10.0 \\
9.1\end{array}$ & $\begin{array}{l}6.5 \times 10^{3} \\
1.2 \times 10^{4} \\
6.9 \times 10^{3}\end{array}$ & $\begin{array}{l}58 \\
53 \\
58\end{array}$ \\
\hline & & 0.8 & 2.7 & $\begin{array}{l}\text { Shearing } \\
\text { around } \\
\text { dent }\end{array}$ & $\begin{array}{l}9.5 \\
8.4 \\
7.5 \\
\end{array}$ & $\begin{array}{l}1.6 \times 10^{4} \\
1.2 \times 10^{4} \\
4.0 \times 10^{3}\end{array}$ & $\begin{array}{l}45 \\
51 \\
57\end{array}$ \\
\hline & 0.6 & 1.0 & 1.7 & $\begin{array}{l}\text { Shearing } \\
\text { around } \\
\text { dent }\end{array}$ & $\begin{array}{l}5.0 \\
5.6 \\
5.2\end{array}$ & $\begin{array}{l}1.5 \times 10^{5} \\
3.3 \times 10^{4} \\
1.3 \times 10^{5}\end{array}$ & $\begin{array}{l}53 \\
47 \\
51\end{array}$ \\
\hline & 0.8 & 1.0 & 1.3 & $\begin{array}{l}\text { Shearing } \\
\text { around } \\
\text { dent }\end{array}$ & $\begin{array}{l}4.0 \\
5.0 \\
4.2 \\
\end{array}$ & $\begin{array}{l}2.7 \times 10^{4} \\
2.9 \times 10^{4} \\
3.1 \times 10^{4} \\
\end{array}$ & $\begin{array}{l}50 \\
40 \\
47 \\
\end{array}$ \\
\hline \multirow{6}{*}{ HSP } & \multirow{4}{*}{0.3} & 1.3 & 4.3 & Tensile & $\begin{array}{l}6.9 \\
7.1 \\
6.1\end{array}$ & $\begin{array}{l}1.0 \times 10 \\
6.5 \times 10^{2} \\
6.9 \times 10\end{array}$ & $\begin{array}{c}113 \\
97 \\
113\end{array}$ \\
\hline & & & & Tensile & 4.8 & $1.4 \times 10^{3}$ & 112 \\
\hline & & 1.0 & 3.3 & $\begin{array}{l}\text { Shearing } \\
\text { around } \\
\text { dent }\end{array}$ & $\begin{array}{l}11.0 \\
11.0\end{array}$ & $\begin{array}{l}7.6 \times 10^{3} \\
5.5 \times 10^{3}\end{array}$ & $\begin{array}{l}37 \\
30\end{array}$ \\
\hline & & 0.8 & 2.7 & $\begin{array}{l}\text { Shearing } \\
\text { around } \\
\text { dent }\end{array}$ & $\begin{array}{l}8.7 \\
8.7 \\
8.7 \\
\end{array}$ & $\begin{array}{l}5.9 \times 10^{3} \\
6.6 \times 10^{3} \\
4.9 \times 10^{3} \\
\end{array}$ & $\begin{array}{l}49 \\
49 \\
49 \\
\end{array}$ \\
\hline & 0.6 & 1.0 & 1.7 & $\begin{array}{l}\text { Shearing } \\
\text { around } \\
\text { dent }\end{array}$ & $\begin{array}{l}5.0 \\
5.0 \\
5.0\end{array}$ & $\begin{array}{l}8.6 \times 10^{4} \\
8.5 \times 10^{4} \\
4.6 \times 10^{4}\end{array}$ & $\begin{array}{l}53 \\
53 \\
53 \\
\end{array}$ \\
\hline & 0.8 & 1.0 & 1.3 & Shearing & $\begin{array}{l}4.0 \\
4.4 \\
4.1\end{array}$ & $\begin{array}{l}2.4 \times 10^{4} \\
5.1 \times 10^{4} \\
3.6 \times 10^{4}\end{array}$ & $\begin{array}{l}49 \\
45 \\
49\end{array}$ \\
\hline
\end{tabular}


bend points bent in two steps was about one cell size or half a cell size. On the other hand, in the crack shown in Figure 5 (c) and the schematic model shown in Figure 5 (e), the crack surface near the center was located in the lower direction as shown in Figure 5 (e). The distant crack surface from the center was located in the upper direction. The crack surface located in the upper direction propagated along the core. Hereafter, the fracture patterns in Figure 5 (b) and (c) are called as the shearing around dent type and the shearing type respectively.

Table 2 shows the list of fracture patterns. The results of HSP have been quoted from existing literature (Kobayashi et al., 2012). Regarding the distance to a crack initiation site, the distance $r$ from the center to the crack initiation site is shown in the case of tensile and shearing type fractures, whereas the distance $a$ from the periphery of the dent to the crack initiation site is shown in the case of shearing around dent type fractures. The method for calculating the stress at the crack initiation site will be described later. It has been recognized from Table 2 that the fracture patterns of the RSP are tensile type when the maximum load is high and the face sheet is thin. On the other hand, the fracture patterns are shearing around dent type when the maximum load is low or the face sheet is thick. Likewise, in the case of HSP, it has been recognized that the fracture patterns are tensile type when the maximum load is high and the face sheet is thin, and shearing around dent type when the maximum load is low or the face sheet is thick. However, shearing type fractures took place when $P_{\max } / h_{f}$ was the lowest in this experiment, where the maximum load $P_{\max }=1.0 \mathrm{kN}$ and the face sheet $h_{f}=0.8 \mathrm{~mm}$. Therefore, it is considered that the fracture patterns will vary if the cores located under the face sheets are different even though the materials of the face sheets used are the same.

\subsection{Effect of fracture patterns on fatigue life}

Figure 6 shows the distribution of fatigue life for fracture patterns by substituting $P_{\max } / h_{f}$ for stress at the crack initiation site in the horizontal axis. Figure 6 reveals that there was no difference in the fatigue life between both panels. Furthermore, the fatigue life of tensile type fractures became longer as $P_{\max } / h_{f}$ became smaller. However, there was no difference attributable to $P_{\max } / h_{f}$ in the fatigue life of the shearing around dent type fractures when $P_{\max } / h_{f}$ was $2.5 \mathrm{kN} / \mathrm{mm}$ or higher. When $P_{\max } / h_{f}$ is $2.5 \mathrm{kN} / \mathrm{mm}$ or less, the fatigue life became longer as $P_{\max } / h_{f}$ became smaller. As an overall tendency, fatigue fractures took place even when the value of $P_{\max } / h_{f}$ was lowered by about one quater from the maximum value of this experiment $(4.3 \mathrm{kN} / \mathrm{mm})$. This was due to changes in the fracture patterns.

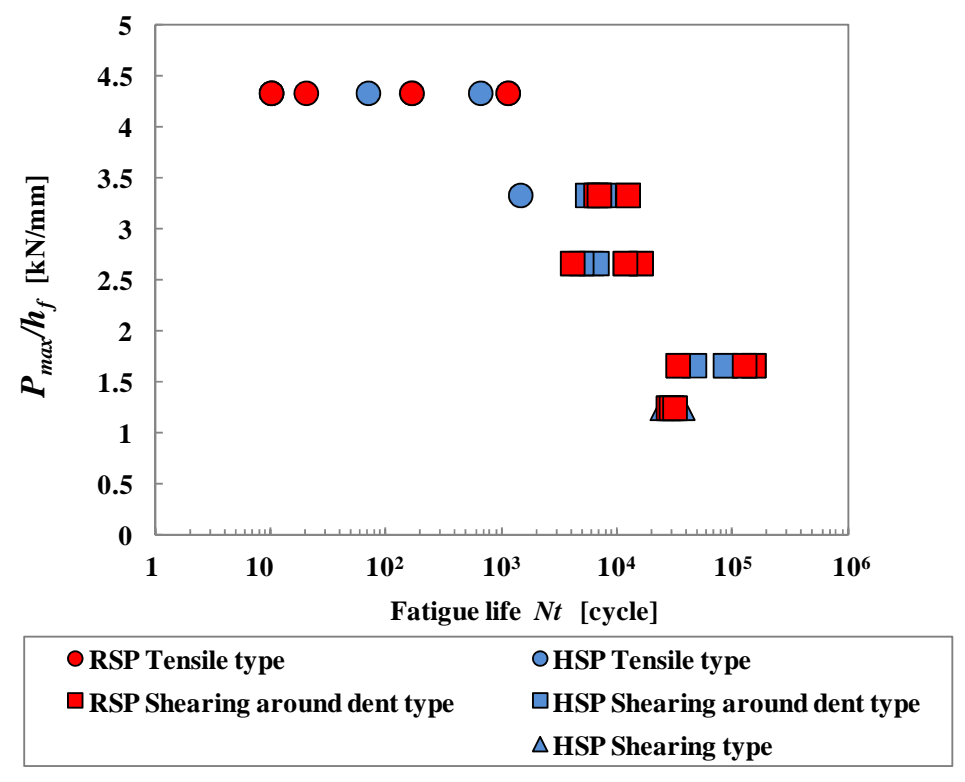

Fig.6 Distribution of fatigue life for fracture patterns.

\subsection{Analysis of stress at the crack initiation site}

Using the calculation method of the maximum deep drawing stress (Fukui et al., 1989), the stresses (tensile stress $\sigma_{\max }$ and shearing stress $\tau_{\max }$ ) at the crack initiation site were calculated with the horizontal distance from the center of the specimen to the crack initiation site $r$ [mm]. 


$$
\sigma_{\max }, \tau_{\max }=\frac{P_{\max }}{2 \pi r \cdot h_{f}}
$$

As observed on fracture surfaces, on the specimen on which shearing around dent type fracture occurred, the crack surface near the center was located in the upper direction and the distant crack surface from the center was located in the lower direction as shown in Figure 5 (d). The crack surface located in the upper direction propagated along the core. Furthermore, the face sheet contacting the indenter bent in two steps at two points, one at the crack initiation site and one on the periphery of the dent. These results indicate that a shearing around dent type fracture occurred with the core acting as a fulcrum (Kobayashi et al., 2012). Furthermore, taking into consideration the fact that the face sheet contacting the indenter exhibited plastic deformation at the center of the dent, it is assumed that there was a small hole at the center. Under these situations, the shearing stress $\tau_{\max }$ at the crack initiation site was able to be determined from the balance of the bending moment around the periphery of the dent. Where, "a" refers to the distance from the crack initiation site to the periphery of the dent. $\mathrm{R}_{\mathrm{A}}$ is a support reaction that acted on the core positioned near the crack initiation site.

$$
\tau_{\max }=\frac{R_{A}-P_{\max }}{2 \pi r \cdot h_{f}}=\frac{\frac{r}{a} P_{\max }}{2 \pi r \cdot h_{f}}=\frac{P_{\max }}{2 \pi a \cdot h_{f}}
$$

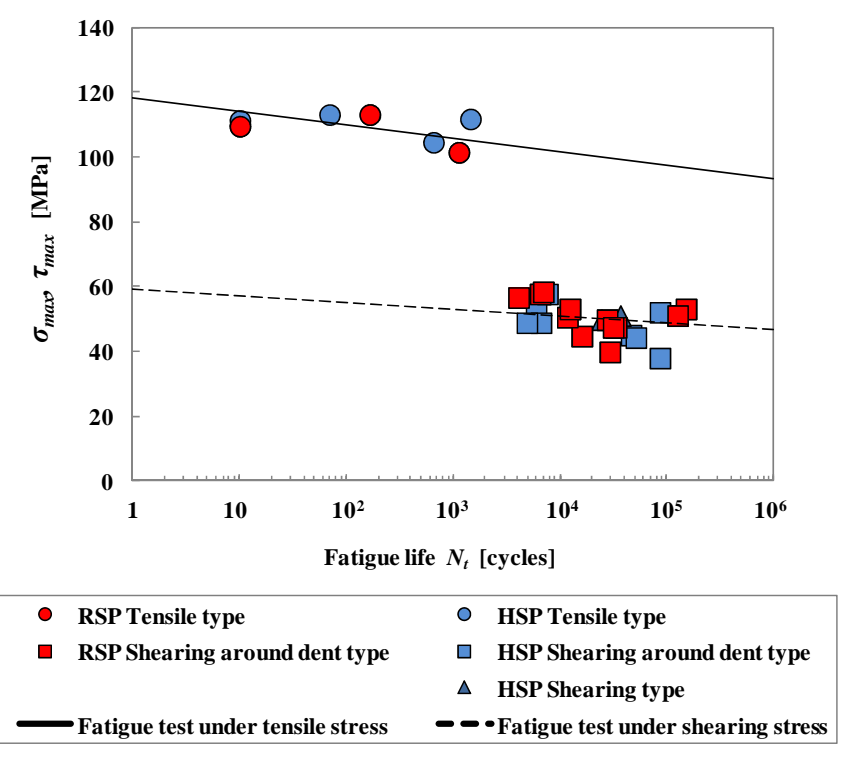

Fig.7 Fatigue life distribution considered stress of crack initiation site.

Figure 7 shows the fatigue life distribution considered the stress of crack initiation site. This figure also shows the fatigue test results under the tensile stress and shearing stress for the A1100 flat plate, which is excerpted from a previous study (Kobayashi et al., 2011). Where, the shearing stress was calculated by $\tau_{\max }=\sigma_{\max } / 2$. In Figure 7 , it is observed that results of the tensile type fracture concentrated near the solid line area, whereas results of the shearing around dent type fracture and the shearing type fracture concentrated in the dotted line area. These results indicate that the fatigue life of RSP and HSP depends on the stress state of the crack initiation site.

\subsection{Criteria for fracture patterns}

The criteria for fracture patterns are explained. Because the floor panel design is a damage tolerant design, the fatigue life is set to $10^{6}$ times in the design. In this case, the condition at which the tensile type fractures take place is the stress range in which the fatigue life is $10^{6}$ times or less as shown by the solid line in Figure 7. 


$$
94 M P a \leq \frac{P_{\max }}{2 \pi r \cdot h_{f}}
$$

As shown by the dotted line in Figure 7, the condition at which the shearing type fractures occur corresponds to the stress range at which the fatigue life is 1 to $10^{6}$ times.

$$
47 \mathrm{MPa} \leq \frac{P_{\max }}{2 \pi r \cdot h_{f}} \leq 59 \mathrm{MPa}
$$

The condition at which the shearing around dent type fractures occur is obtained in the same way as that for the shearing type fractures.

$$
47 M P a \leq \frac{P_{\max }}{2 \pi a \cdot h_{f}} \leq 59 M P a
$$

The conditions in which the shearing around dent type fractures occur more easily than tensile type fractures, the maximum shearing stress $\tau_{\max }$ obtained through Equation (5) must be less than the maximum tensile stress $\sigma_{\max }$ obtained through Equation (3). The following conditions are obtained.

$$
\begin{aligned}
& \frac{P_{\max }}{2 \pi r \cdot h_{f}} \leq 2 \times \frac{P_{\max }}{2 \pi a \cdot h_{f}} \\
& \frac{a}{2} \leq r
\end{aligned}
$$

In addition, the following relationship is obtained on the basis of the hypothesis that the crack initiation site geometrically depends on the shape of the indenter (Kobayashi et al., 2011, 2012).

$$
r=\alpha \sqrt{2 R I \cdot\left(\beta \frac{P_{\max }}{h_{f}}\right)-\left(\beta \frac{P_{\max }}{h_{f}}\right)^{2}}
$$

In this study, $\alpha$ is 0.41 and 0.43 for RSP and HSP respectively. $\beta$ is $0.9 \mathrm{~mm}^{2} / \mathrm{kN}$ for both panels. The differences of $\alpha$ is considered as the follows. If cores under beneath the peripheral of dent supported the reaction, the circumference for peripheral of dent is inversely proportional to the compressive strength in the thickness direction of core. When the circumference for peripheral of dent was small, an indentation depth of indenter becomes small. When the indentation depth of indenter was small, an area contacting the face sheet and the indenter becomes small. Therefore, the distance between the center and the crack initiating site $r$ becomes smaller, because the area contacting the face sheet and the indenter is approximated by $\pi r^{2}$.

Figure 8 illustrates the criteria for fracture patterns. As seen in Figure 8, experimental results for each fracture pattern were plotted in the regions of each fracture patterns obtained from equations (3) (7). Therefore, predictions for a potential fracture are allowed by using these criteria. Moreover, it is considered that the reason of no difference of the fatigue lives between RSP and HSP with different compressive strength in the thickness direction of core and different cell size as shown in Fig. 6 is because the difference of parameters $\alpha$ for both panels was small.

For the distance "a" between the periphery of the dent and the crack that corresponds to the shearing around dent type fracture, the experimental value was given as input data in Equation (5). From the observations of fracture surfaces, these distances were about the size of a single cell or half of a cell. For the simplicity of the design, it is considered that the size of a single cell or half of that value is useable as the distance "a". This also means that the fracture pattern and the fatigue life depend on not the shape of the cell but the cell size.

Finally, the reasons for the occurrence of the shearing type fracture only in HSP in this study are considered. The reason for this is because the region for $P_{\max } h_{f}$ in which the shearing around dent type fractures can occur is small in 
the roll core, which has a larger cell size, as shown in Figure 8.

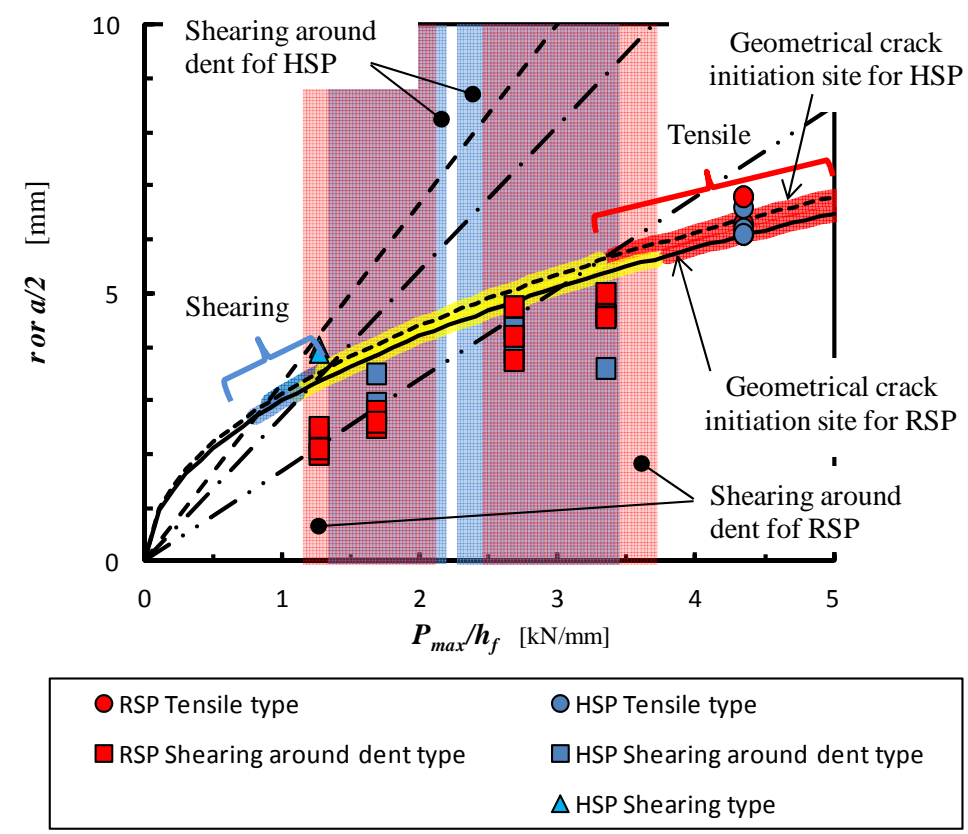

Fig. 8 Criteria for fracture patterns. The vertical axis in the figure represents the distance between the center and the crack initiating site " $r$ " or half of the distance from the crack initiation site to the periphery of dent " $a / 2$ " when equation (6) is considered. The horizontal axis indicates a parameter corresponding to the stress " $P_{\max } / h_{f}$ ". The relationship between " $r$ " and " $P_{\max } / h_{f}$ " obtained from Equation (7) is shown using solid and the dotted lines for RSP and HSP, respectively. In addition, the areas where the tensile type fractures, shearing type fractures, and shearing around dent type fractures can occur are shown, which are obtained using Equations (3)-(6). The region shown by the solid or dotted lines on the right side of the double dot dash line (red bold line) is the region in which tensile type fractures can occur. The region shown by the solid or dotted lines between the single dot dash and dotted lines (light blue bold line) is the region where the shearing type fractures can occur. In addition, the red or blue regions located below the solid line or dotted line obtained by Equation (7) are the regions where the shearing around dent type fracture can occur in RSP(red) or HSP (blue).

\section{Conclusions}

By conducting local compression fatigue tests on peripherally clamped roll core sandwich panels and honeycomb core sandwich panels for material comparison, and examining the local compression fatigue properties, the following results were obtained:

1) Three types of fracture patterns for the honeycomb core sandwich panels were observed: tensile type, shearing type and shearing around dent type. For the roll core sandwich panels, there were two types: the tensile type and shearing around dent type.

2) It was found that the fatigue fracture occurred for both panels even though the $P_{\max } / h_{f}$ values were lowered by about four times. This was due to the fracture pattern changing from the tensile type to the shearing around dent type or shearing type. 
3) The local compression fatigue life for both panels depends on the stress state of the face sheet contacting the indenter. It is possible to calculate the stress state for each fracture pattern.

4) The fracture pattern and fatigue life depend on not the shape of the cell but the cell size.

5) The criteria of the tensile type, shearing type, and shearing around dent type fatigue fractures were theoretically explained. Design guidelines used the criteria were proposed.

\section{References}

Fukui, S., Takeyama, H., Yoshida, K. and Abe, K., On the Working Limit for Deep-Drawing, Transactions of the Japan Society of Mechanical Engineers, Vol.55, No.405(1952), pp.640-646, (in Japanese).

Goldsmith, W. and Sackman, J. L., An experimental study of energy absorption in impact on sandwich plates, Inernational Journal of Impact Engng., Vol.12, No.2(1992), pp241-262.

Kobayashi, Y., Ohtsuka, T., Kishimoto, Y., Inuma, S. and Ohtsu, Y., Effect of Cell Wall Thickness on Local Compression Fatigue Property of Honeycomb Core Sandwich Panel, Transactions of the Japan Society of Mechanical Engineers, Series A, Vol.78, No.787 (2012), pp.299-310, (in Japanese).

Kobayashi, Y., Ohtsuka, T., Tuduku, T. and Kishimoto, Y., Compression Property of Roll Core Sandwich Panel, Transactions of the Japan Society of Mechanical Engineers, Series A, Vol.76, No.771 (2010), pp.1429-1435, (in Japanese).

Kobayashi, Y., Ohtsuka, T., Tujita, M., Abe, Y. and Kishimoto, Y., Local Compression Fatigue of Peripherally Clamped Honeycomb Sandwich Panel, Transactions of the Japan Society of Mechanical Engineers, Series A, Vol.77, No.775 (2011), pp.415-426, (in Japanese).

L. J. Gibson and M. F. Ashby, “Cell Structures”, Uchida Rokakudo Publishing Co., LTD(1993), pp.97-160.

Miyairi, H., Introduction to Sandwich Structures, (1999), pp.17-28., The Nikkan Kogyo Shinbun LTD, (in Japanese).

Moriarty, K. and Goldsmith, W., Dynamic energy absorption characteristics of sandwich shells, International Journal of Impact Engng., Vol.13, No.2(1993), pp.293-317.

Noguchi, H., Production Method and Application of Honeycomb Material, Bulletin of the Japan Institute of Metals, Vol.24, No.6(1985), pp.471-479, (in Japanese).

Society for the Advancement of Material and Process Engineering ed., Development \& Application of Honeycomb Core Materials \& Sandwich Structures, (1995), pp.125-158, CMC.

Takeichi, Michifumi, Okuno, S., Okazaki, M. and Tsuruda, H., Strength Properties of an Aluminum Alloy Car Body Structure for High Speed Railway Vehicle(1st Report, Static Strength Properties of an Aluminum Alloy Honeycomb Sandwich Panel and Strength Reliability Evaluation of an Actual Car Body Structure), Transactions of the Japan Society of Mechanical Engineers, Series A, Vol.68, No.666(2002a), pp.319-326, (in Japanese).

Takeichi, M., Okuno, S., Okazaki, M. and Tsuruda, H., Strength Properties of an Aluminum Alloy Car Body Structure for High Speed Vehicle(2nd Report, Fatigue Strength Properties of an Aluminum Alloy Honeycomb Sandwich Panel and Strength Reliability Evaluation of an Actual Car Body Structure), Transactions of the Japan Society of Mechanical Engineers, Series A, Vol.68, No.666 (2002b), pp.327-334, (in Japanese).

Takeichi, M., Okuno, S., Tsuruda, H., Okazaki, M. and Hirose S., Strength Properties of an Aluminum Alloy Car Body Structure for High Speed Vehicle(3rd Report, Strength Reliability Evaluation of an Actual Car Body Using Fatigue Test of an Experimental Car Body under Pressure Load), Transactions of the Japan Society of Mechanical Engineers, Series A, Vol.68, No.666 (2002c), pp.335-342, (in Japanese).

Tujita, M., Kobayashi, Y. and Ohtsuka, T., Local Compression Fatigue of Phripherally Clamped Double Layer Honeycomb Core Sandwich Panel, Transactions of the Japan Society of Mechanical Engineers, Series A, Vol.75, No.758 (2009), pp.1416-1423, (in Japanese).

Watanabe, M., Ohtsuka, T., Tamura, H. and Kobayashi, Y., Study on the Impact Property of the Honeycomb Sandwich Panel, Transactions of the Japan Society of Mechanical Engineers, Series A, Vol. 69, No.678 (2003), pp.257-264, (in Japanese). 